\title{
Evolution of Biochemical Diagnosis of Acute Coronary Syndrome - Impact Factor of High Sensitivity Cardiac Troponin Assays
}

\author{
Amparo Galán¹, Josep Lupón² and Antoni Bayés-Genis² \\ ${ }^{1}$ Biochemical Service \\ ${ }^{2}$ Cardiology Service, \\ España
}

\section{Introduction}

In patients with acute thoracic pain and non-conclusive acute myocardial infarction electrocardiogram (non-STEMI), the biochemical diagnosis is an essential tool for its correct treatment. The study of the chosen biomarker for cardiac injury has raised interest during decades. The appearance of immunoassays to assess cardiac troponin I or T has reached great improvements in the diagnosis, evolution and prognosis of the Acute Coronary Syndrome (ACS), as well as in risk stratification of these patients and in patients with chronic cardiac diseases as heart failure or cardiomyopathies. Regarding the analytical sensitivity of the methods that evaluate cardiac troponin I or T these improvements have made possible to measure accurately very tiny seric concentrations of the protein (high sensitivity troponin) (hs-Tn). This fact, being positive in principle sometimes induces to reconsider if tiny seric concentrations of isolated troponin $\mathrm{I}$ or $\mathrm{T}$ are not due to acute myocardial infarction but to a less severe source which affects the myocardiocite, this will oblige us to assess the clinical presentation in depth.

\section{Diagnostic criteria of acute coronary syndrome - Biochemical markers - History background and evolution}

Thoracic pain is one of the most frequent reasons for attending the emergengy room at hospitals. About 10\% of these patients will be diagnosed Acute Myocardial Infarction. The clinical syntoms and the electrocardiogram can not always differentiate between a patient suffering from acute myocardial infarction or an angina. Electrocardiogram is only diagnostic in $40 \%$ of the patients. That is why in processes of acute coronary ischemia different from infarction with rising of segment ST, (infarction no $\mathrm{Q}$ or without rising of ST, unstable angina), the use of biochemical markers can be the only criteria to identify the existence of myocardial necrosis, being necessary for infarction diagnosis, treatment, evolution and prognosis.

The biochemical diagnosis of acute coronary syndrome has had remarkable changes over the last few years. During years the enzymatic profile (creatine kinase, activity of the isoenzime $\mathrm{CKMB}$, aspartate aminotransferase and lactate deshidrogenase) has been the 
biochemical method chosen for the diagnosis of acute coronary ischemia. The criteria of the WHO (WHO 1979 ) was followed until 1999, being the catalytic activity of creatine kinase $\mathrm{MB}$ isoenzyme (CKMB) the marker chosen. In fact, according to the WHO to reach the diagnosis of acute myocardial infarction (AMI) two of the following three criterias must be fulfilled: precordial pain with evolution longer than 30 minutes, specific electrocardiograph changes and elevation of catalityc activity of creatine kinase (CK) and its isoenzime $\mathrm{MB}$ (CKMB).

However, during the 1990s more sensitive and specific cardiac markers are marketed and beginning to be used in order to detect the disease, such as the protein concentration of isoenzime MB (CKMBmass) or Troponin.

In September 2000 the criteria which defines acute myocardial infarction (AMI) was reviewed and a consensus document was published (European Society of Cardiology/ American College of Cardiology Committe 2000) between The Joint European Society of Cardiology and The American College of Cardiology where they give great importance to the alterations of cardiac markers: Troponin or CKMBmass (no activity) for the diagnosis of the disease, together with symptoms of ischemia or alterations in the electrocardiogram (ECG). In fact, the main criteria to establish the diagnosis of acute myocardial infarction is to verify the gradual release of troponin or CKMBmass, (typical curve of fast rising-descent), together with at least one of the following alterations: a) ischemic syntoms; b) development of pathological Q waves in ECG; c) indicative changes of ischemia (variations of the segment $\mathrm{ST}, \mathrm{T})$

\subsection{Cardiact troponin: Biochemical bases}

Troponin is one of the myofibrilar proteins of the skeletal muscle and its function is to regulate muscular contraction in relation with calcium ion (Figure 1). The thick filament of the muscle is formed by myosin and the thin filament by actin, troponin and tropomyiosin. Only actin and myosin are contractile proteins; troponin and tropomyosin are regulatory. Troponin is composed by three peptides called troponin T, troponin I and troponin C. Troponin $\mathrm{T}$ is regulatory of tropomyosin; troponin I (inhibitory), inhibits the union actinmyosin; troponin $\mathrm{C}$ is the receptor of calcium so when linking calcium disappears the inhibition of troponin I on tropomyosin forming the shuttles actin-myosin and activating the contraction.

The theory currently accepted for the mechanism of muscular contraction involves the ATPasic activity (two molecules of ADP and inorganic phosphorus) present in the heads of myosin (figure 1). In repose myosin does not contact actin as the sarcplasm does not have enough calcium to produce the contraction, and calcium regulates the ATP-asic activity. During the contraction when receiving the nervous signal calcium is released to the sarcoplasm, this calcium joins immediately to the centers of union of calcium to troponin, inducing a structure change which allows the heads of actin and myosin to link forming an angle of about $90^{\circ} \mathrm{C}$. The release of the phosphorus molecule of the complex actin-myosinADP involves a structure change which makes actin slide (power strike) and adopt a $45^{\circ} \mathrm{C}$ angle on myosin. This movement produces at the same time a release of ADP. For each actin myosin union provoked by the union of two calcium molecules to troponin $\mathrm{C}$, at least two ATP molecules are needed and to carry two calcium molecules from the cytosol to reticule an ATP molecule is required (Galán A. 2000). 


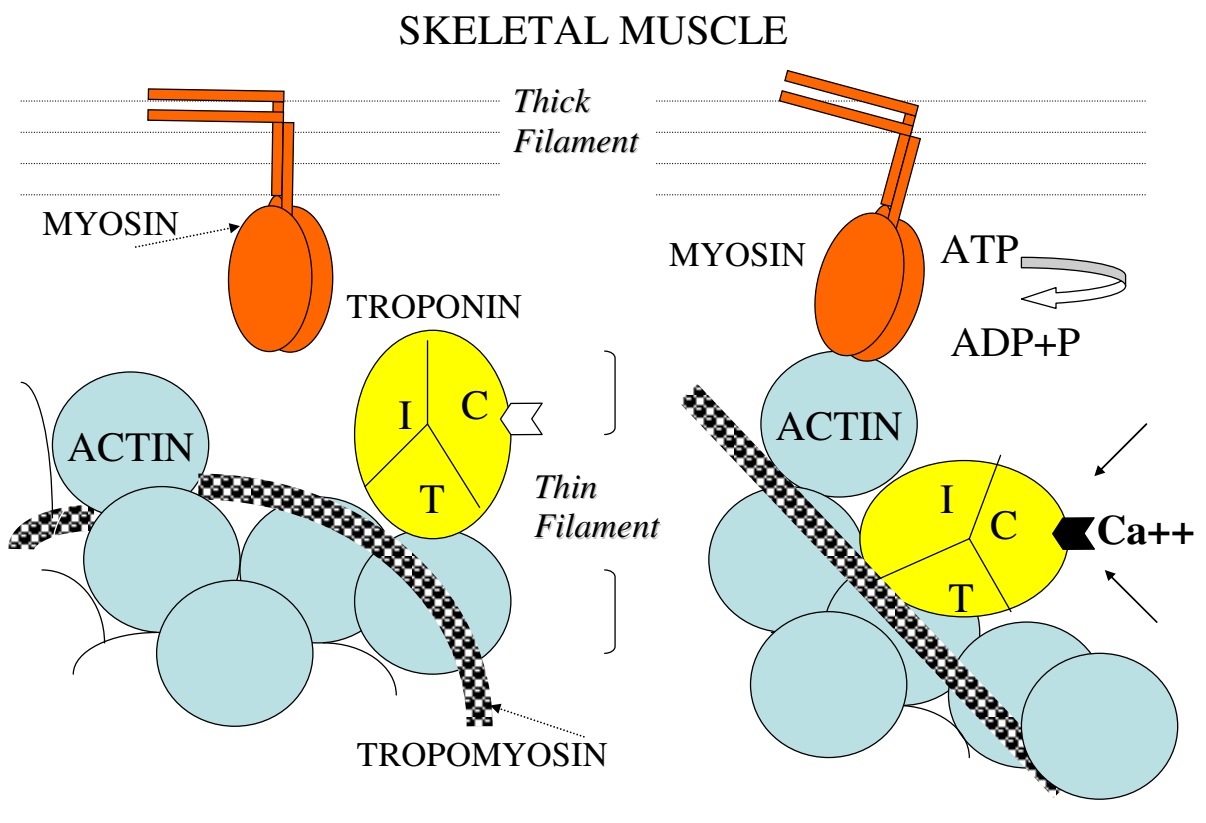

REPOSE

CONTRACTION

ADP: Adenosin diphosphate

ATP: Adenosin Triphosphate

Fig. 1. Scheme of the process of muscular contraction and involvement of myofibrilar and contractile proteins of the skeletal muscle (Galán A. 2000).

The different kinds of muscles of the organism present different characteristics of contraction, this is due to the structural differences genetically determined in some myofibrilar proteins. Three isoforms have been described for troponin I and T which present structural differences codified by genes located in three different crhomosomes. So for troponin I (figure 2) there are two isoforms of the skeletal muscle one of slow contraction and another one fast and a specific shape of the cardiac muscle. The cardiac isoform has 31 suplementary aminoacids at the N-terminal end of the polypeptide chain and besides it differs from skeletal isoforms as it shows in the tracts of the primary sequences of the protein, a heterogeneity of $69 \%$ for the central tract (residues 30 to 110) and $44 \%$ for the terminal tract (110-215) which seems to be more stable because of the protection carried out by the subunit $\mathrm{C}$ terminal. Troponin $\mathrm{T}$ also shows three isoforms codified by genes located in three different chromosomes, one of them is specific for myocardium. The myocardial isoform has an elevated polymorphism provoking isoforms which express in injured myocardial tissue, adult and fetal. Troponin C, however, is identical in both kinds of muscle. (Galán A. 2004).

This fact confers troponin the qualification of cardiac marker of maximum cardiospecificity unlike creatine kinase, creatine kinase $\mathrm{MB}$ and myoglobine which co-express in the skeletal 
muscle and in the myocardium. Some specific anti-bodies have been patented in opposition to troponin $\mathrm{T}$ and cardiac Troponin I so that they can be recognised by specific immunoassays. Troponin forms (I and T) of skeletal and cardiac muscle: a) Are codified by different genes; b) Have structures which are clearly differentiated; c) Are recognised by specific immunoassays.

That is why the assessment of troponin $\mathrm{T}$ or troponin I favours the specific recognition of myocardial damage even in the presence of concomitant skeletal muscle damage. Therefore only troponin molecules fulfil the cardiospecificity criteria. This cardiospecificity guarantees that the detection of a cardiac troponin molecule in plasma is indicative of myocardial injury.

\section{ISOFORMS OF TROPONIN I}

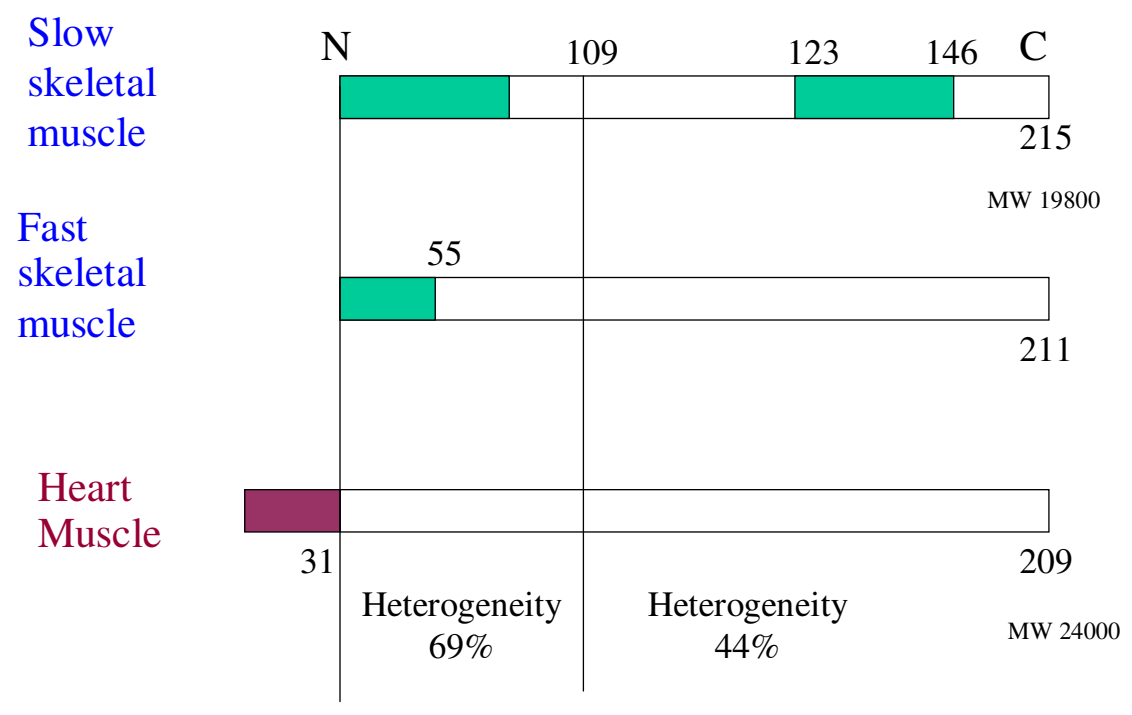

Fig. 2. Isoforms of Troponin I: In the figure we can see two isoforms of skeletal muscle, one of slow contraction and another one fast and a specific form of cardiac muscle. The cardiac isoform has 31 suplementary aminoacids at the end N-terminal of the polypeptide chain, besides it differs from skeletal isoforms as it shows in the tracts of the primary sequence of the protein a heterogeneity of $69 \%$ for the central tract (residues 30 to 110) and $44 \%$ for the terminal tract (110-215) which seems to be more stable because of the protection carried out by the subunit C terminal (Galän A 2004).

We confirmed the absence of crossed reactions (Galán A. 2002) for an Immunoassay Troponin I (cat. $\mathrm{n}^{\circ}$ RF421 Dade Behring) using the Dimension RxL automatic analyzer (Dade Behring, Newark, Delaware, USA). The cardiospecificity of troponin I was verified using 
myocardial and skeletal muscle (quadriceps, biceps) tissue. Troponin I was measured in myofibrillar and cytosolic fraction. The absence of troponin I in skeletal muscle was corroborated: the concentration of troponin I in biceps and quadriceps was not detected (< $1 \%$ of the values obtained in myocardial tissue). The troponin I concentration in the myofibrillar fraction of cardiac tissue was $7.2 \mathrm{mg} / \mathrm{g}$ protein and only $4 \%$ of total troponin content was found in the soluble fraction (figure 3 ).

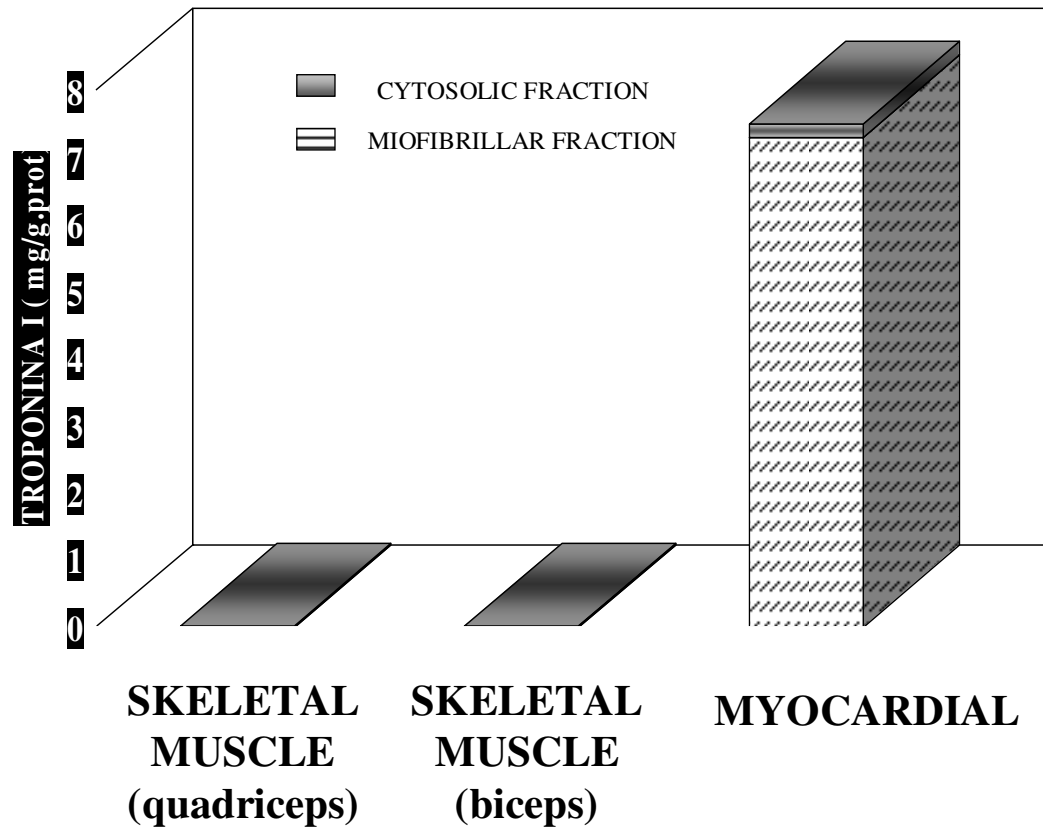

Fig. 3. Tissue specificity for the troponin I method. The figure shows the lack of crossreactivity of troponin I with skeletal muscle. No troponin I concentrations in the crude extract of biceps and quadriceps were detected. The troponin I concentration in the myofibrillar fraction of cardiac tissue was $7.2 \mathrm{mg} / \mathrm{g}$ protein and in the cytosolic fraction 0.3 mg/g protein. (Galán A. 2002)

This fact helps to understand the double diagnostic window of troponin: The small fraction dissolved in cytoplasma of the cardiomyocites, which has relative precociousness ( $>6$ hours) in the detection of cellular injuries (similar to other cytoplasmatic proteins) and the majority fraction which is the one linked to tropomyosin complex in structure and only appears in plasma after cellular irreversible damage and after 40 hours from occurring and remains elevated till 10-15 days after the injury, being then used as late marker of myocardial necrosis (figure 4) 


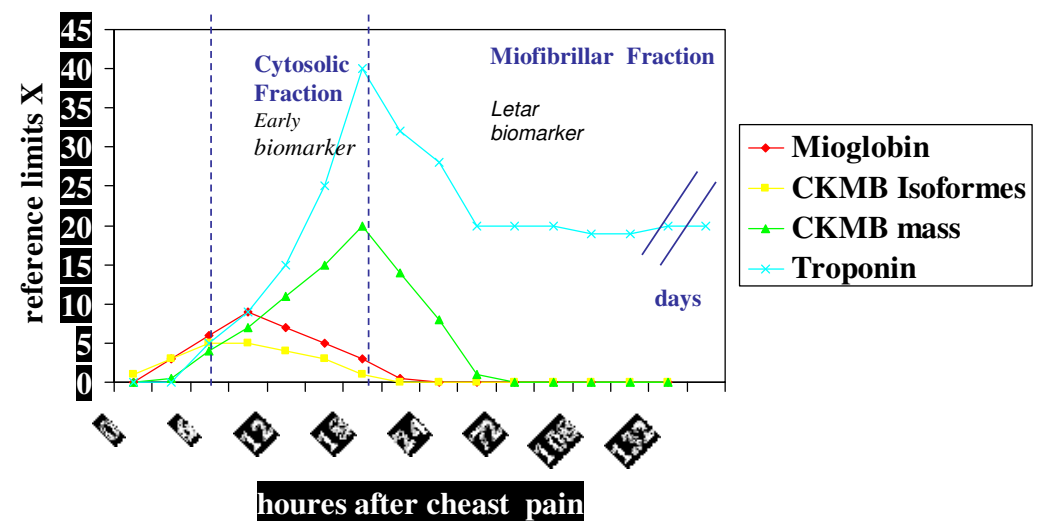

Fig. 4. Plasmatic levels of cardiac markers after ischemic process: Double diagnostic window of Troponin

\subsection{Comparative characteristics of troponin with other cardiac markers}

Myoglobine and CKMB are located in the cellular cytoplasma which favours a fast exit of the molecule out of the cell and therefore an early appearance in systemic circulation. Troponin has a small fraction in cellular cytoplasma but most of it is found in deep tissue, as part of tropomyosin complexes. On the other hand either myoglobin or CK-MB co-express in skeletal muscle so they do not have the cardiospecificity which troponin shows (Table 1).

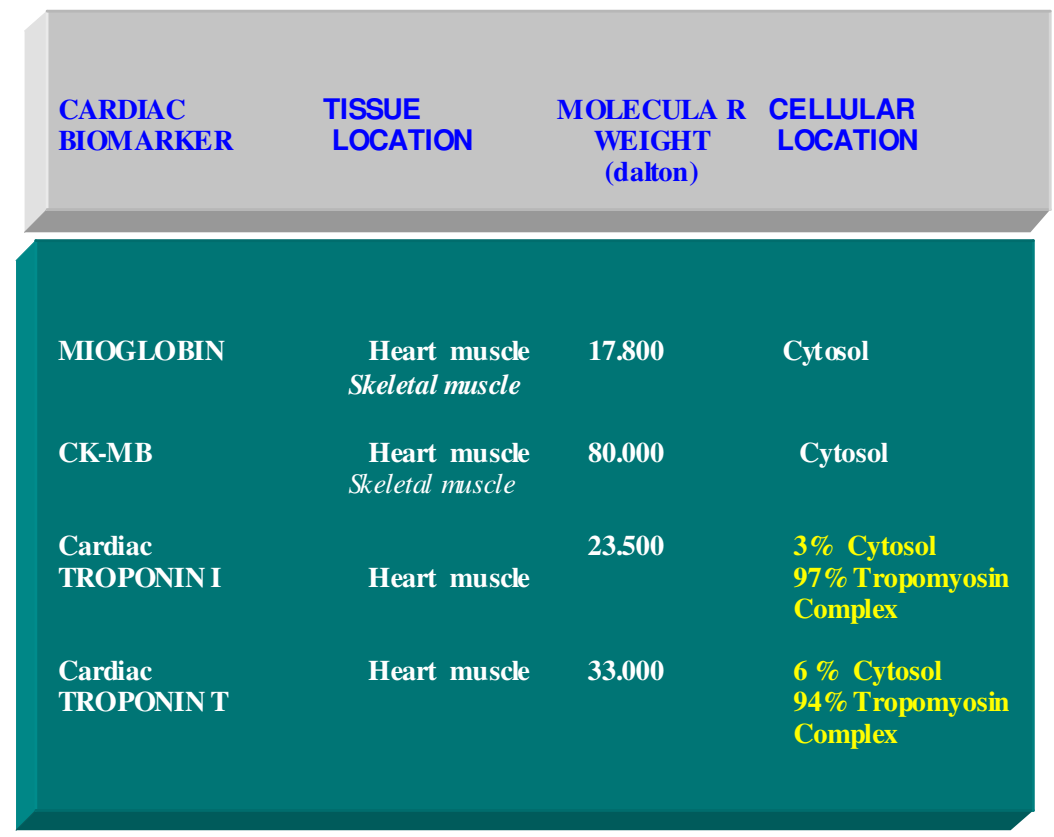

Table 1. Molecular Weight and cellular and tissue location. 
Myoglobin and CK isoforms are the earliest markers and with the fastest elimination. CKMB is cytosolic but it has higher PM than Myoglobin so it takes it longer to appear and clear the plasma. Troponin, due to its double location has a wide diagnostic window (from 6 hours to 10-12 days) (Table 2 )

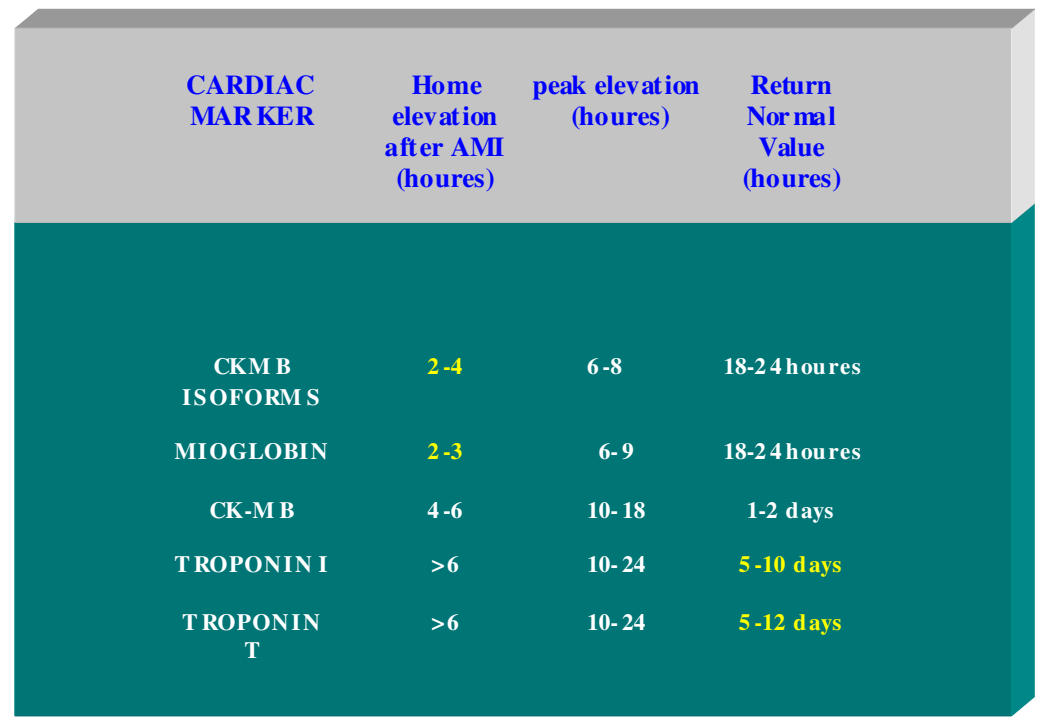

Table 2. Cardiac marker Kinetics.

Cardiac troponin has a small fraction (6\% for T and 3\% for I) dissolved in cytoplasma of the cardiomyocites. This confers the early detection of cellular damage similar to that of other cytoplasmatic proteins, even better than the isoenzime $\mathrm{MB}$ of creatine kinase because its molar mass is lower $(33.000 \mathrm{~g} / \mathrm{mol}$ para la T y $23.500 \mathrm{~g} / \mathrm{mol}$ para la I). Nevertheless, the majority fraction, approximately $90 \%$, is linked in structure to the tropomyosin complex and only appears in plasma after irreversible cellular damage and 40 hours after occurring. Besides, as it remains in plasma for a long time it can also be used as late marker of myocardial necrosis.

Because of all of this, the excellent cardiospecificity and sensitivity of troponin for the detection of myocardial necrosis, together with its wide diagnostic window (from 6-12h to 510 days for troponin I and from 6-12 hours to 5-15 days for troponin T) have revolutionised in the latest years the approach of patients with acute coronary syndrome as a lot of studies have demonstrated its usefulness in the diagnosis of myocardial necrosis as well as in the prognostic stratification of these patients in the first hours of evolution.

\subsection{Problem of the methods to assess troponin. Solutions taken. Guidelines for clinical practice 1999 and 2001}

In the beginning of working with troponin, either physician or biochemists wondered : Is troponin so useful?, Which troponin method is the right one? (Troponin T or Troponin I), What cut-off must we choose?, What marker or markers must be selected?, What intervals must be used? 
At present there are black spots in the analytical management of the methods which assess troponin as the election for cut-off or the lack of standardization of the different methods available in the market (Wu Alan HB 2001), (Apple FS, 2001) and the low analytical sensitivity of the methods among others. These factors may cause confusion in the election of the method as well as in the clinical interpretation of the results (Table 3).

- The choice of cutoff

- Lack of Tn I method's estandarization

- Low sensitivity of methods

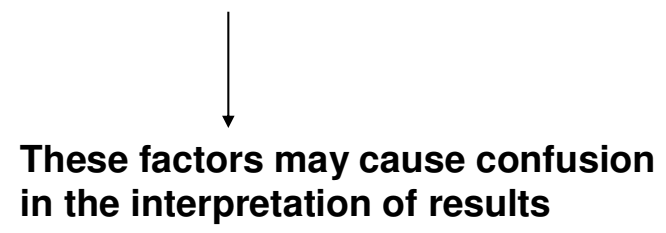

Table 3. Technical problems in management troponin methods.

To try to help and encourage us to use troponin, in 1999 appeared the first Guidelines for Clinical Practice in the use of troponin published by the National Academy of Clinical Biochemistry (NACB) to establish analytical and clinical recommendations (Wu AHB 1999) and in 2001 the standardization committee of cardiac markers of the International Federation of Clinical Chemistry (IFCC) opted for troponin as election marker for myocardial necrosis and establishes recommendations of analytical and pre-analitical quality for the assays of Tn, ( Panteghini M 2001), encouraging the clinical laboratories to use it and inducing the manufacturers to improve the analytical quality of the methods of assessment of the protein.

An example of the problems was the discrepancy arisen when establishing the cut-offs according to the criteria of the different scientific societies: The NACB suggests using the ROC curves of sensitivity and diagnostic specificity choosing two cut-offs (AMI and myocardial damage) or just one cut-off of myocarid damage. Another alternative is to establish Reference Values in normal population and apply 95th percentile as the National Academy of Clinical Biochemistry (NACB) suggests or 99th percentile as the American College of Cardiology suggests (ACC).

Another important problem is the election of the method (table 4). There is only one method in the market to measure TnT and innumerable methods to measure Tn I. The results of the different methods which measure Tn I are not overlapping, which generates doubts about its election. This variability of results does not occur with TnT methods as there is only one TnT immunoanalisis marketed. However, TnT values are not overlapping either with the methods which measure Troponin I. The molecular structure of TnI favours its heterogeneity. In serum there is variability of forms of TnI by oxidation, phosphorilation or protelisis affecting the interaction with anti-bodies in the assays. Besides, the heterogeneity in plasma of the different forms of troponin is another reason that makes it difficult to select the method. In blood we can find tissular forms of troponin making binary or ternary troponin complexes and free cytosolic forms (Figure 5). Therefore the anti-bodies used in the immunoassays of TnI detect different epitopes in free and complexed forms. 
- Heterogeneity in plasma of the different forms of troponin

- Tissular forms:

binary troponin complexes $(\mathrm{I}+\mathrm{C})$

ternary troponin complexes $(\mathrm{T}+\mathrm{l}+\mathrm{C})$

- Free cytosolic forms (I and $\mathrm{T}$ )

- There is any reference material to standardize marketed troponin methods

- The antibodies used in the immunoassays of Tnl detect different epitopes in free and complexed forms.

Table 4. Reasons difficult the election of the method.

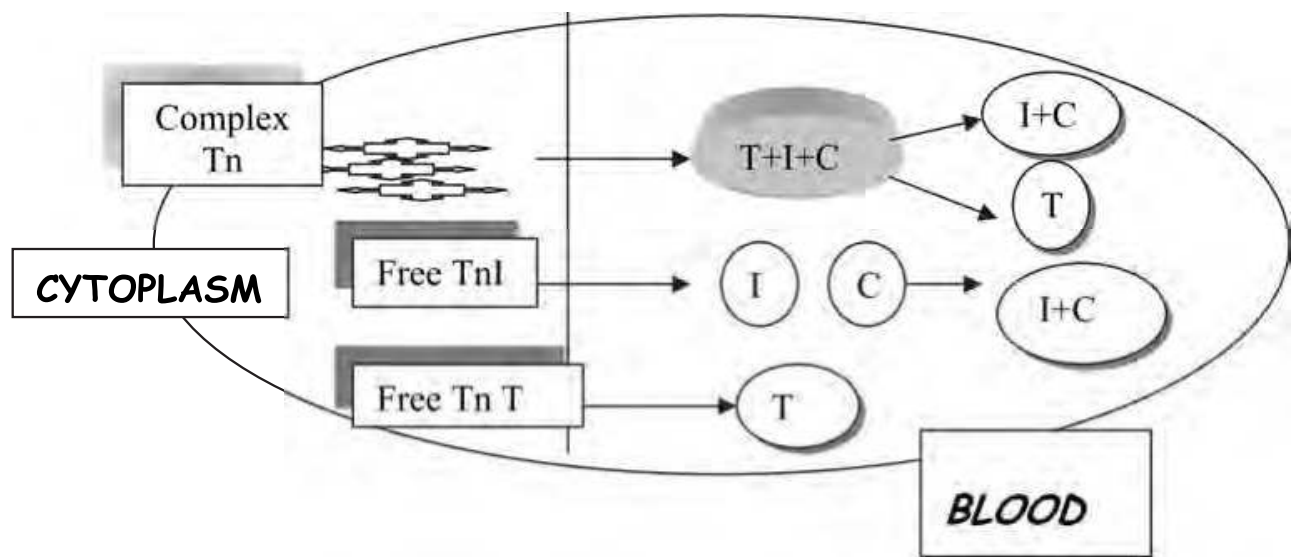

Fig. 5. Scheme of the release in blood of cardiac sub-units of troponin after acute myocardial infarction (according to Wu y cols.) (Galan2004).

So the main problem regarding the methods that assess troponin is the lack of standardization (Figure 6). As a consequence of that there is no transferring of the results among the different commercial methods which assess this protein, what creates confusion due to the analytical and clinical variability of the results. This makes it difficult to choose the best method.

The absence of a material of reference which standardizes the methods means that the results obtained can not be transferred. The methods will have a different cut-off, variations in the limit of the cut-off, as well as imprecisions. On the other hand at low levels close to the reference values the coefficients of variation are elevated.

The most suitable solution in the long run, as it is a difficult matter, to solve this problem is to obtain international reference material, a topic in which scientific societies as IFCC and AACC (American Society of Clinical Chemistry) among others have been working on since 2001. This would standardize the methods and the transferring of the results would be achieved. What would not be unified is the variation of anti-bodies every manufacturer uses. The problem is not completely solved as the reference material obtained, more suitable, was elaborated by a sub-committee of standardization of the AACC in 
collaboration with the National Institute of Standards and Technology (NIST) and certified in 2006 as standard reference material SRM \# 2921. This reference material achieves commutability only with $50 \%$ of the commercial methods which assess troponin. In any case, the standardization of the measurement methods of troponin is not finished yet, which involves wide analytical variations noticed among the different immunoassays marketed and appoved by the FDA. (Wu Alan HB 2001).
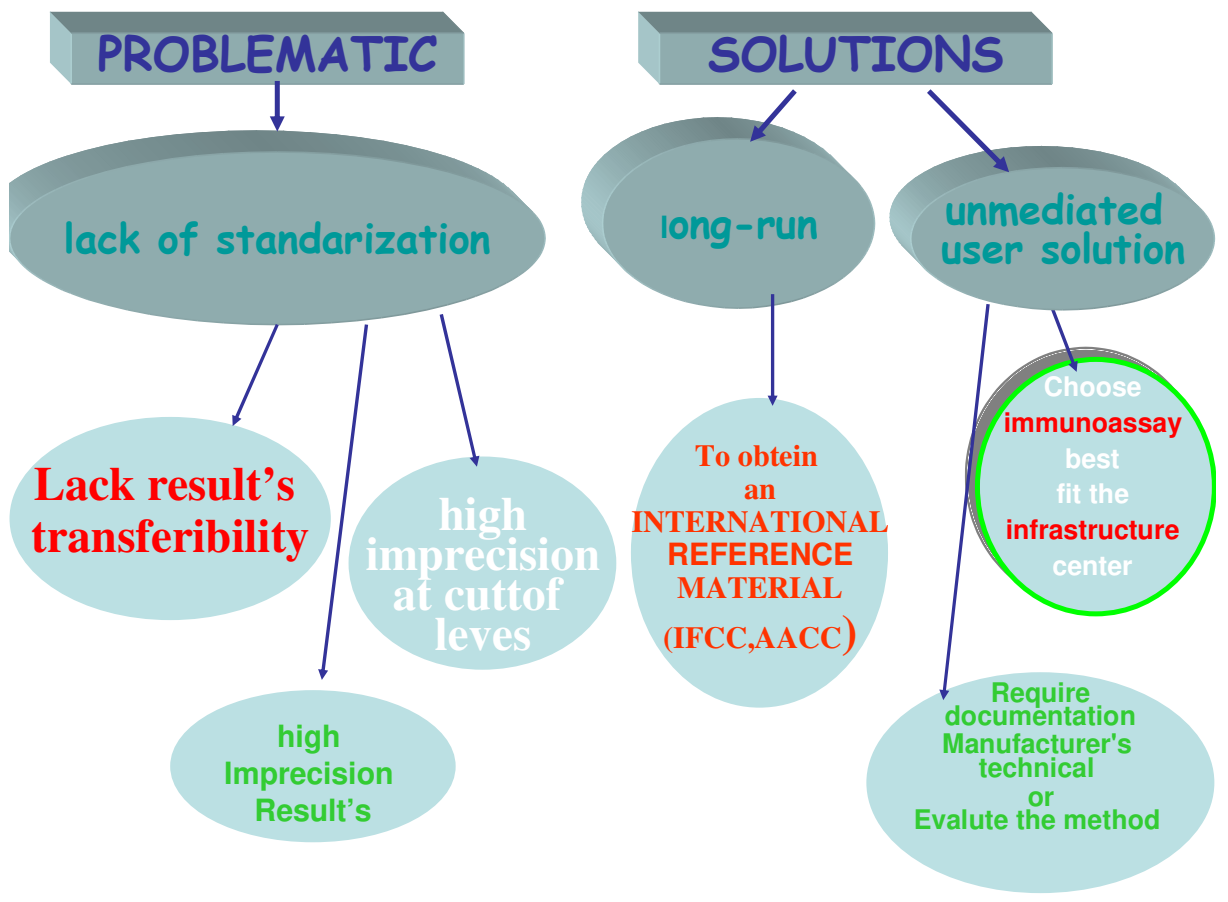

Fig. 6. Analitical problems of the methods which assess troponin: Absence of standardization of the methods.

The immediate solution the user must opt is: Choose the immunoassay which best adapts the infrastructure of the centre (central laboratory, emergency laboratory, or at the patients' side) (bear in mind the analytic system available) and demand the manufacturers the technical documentation about what their method measures. The black spots must be evaluated by the user itself. In case that the imprecision of the chosen method does not fulfil the NABC indications at the point of diagnostic decision, the improvement of the method must be claimed to the manufacturer.

Another important shortage of the initial methods of quantification of troponin is its relative sensitivity (figure 7) 
Figure 7. PROBLEM OF INITIAL TROPONONIN METHODS

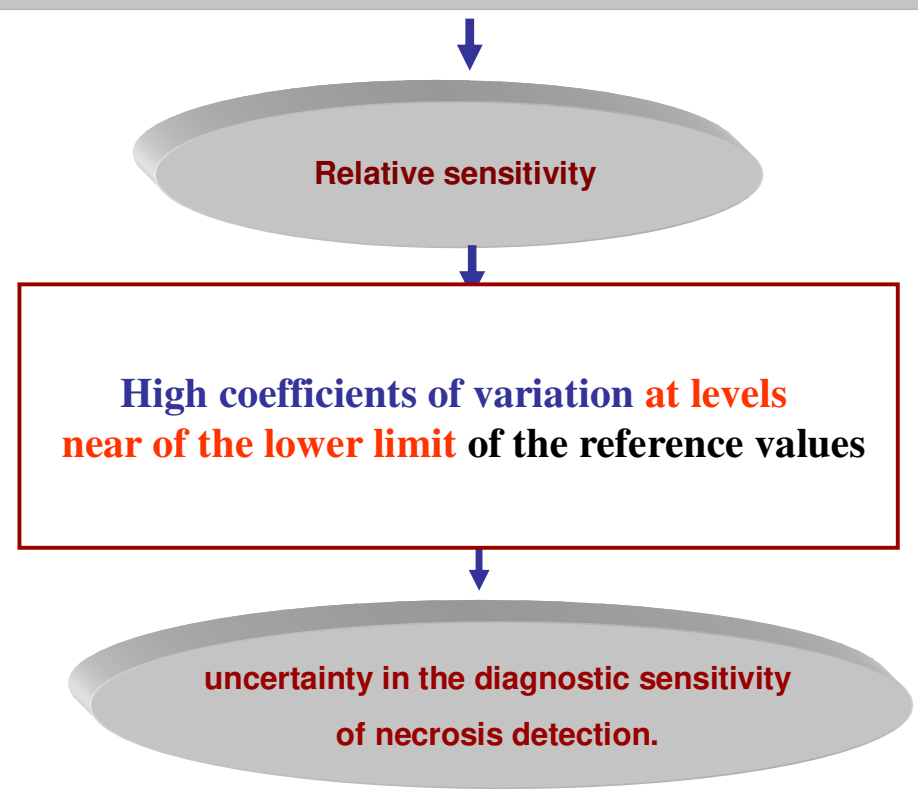

Fig. 7. Problem of initial troponin methods.

In general the methods of assessment of troponin showed elevated values in the limits of detection, limits of quantification far from the reference values, high imprecisions in the limits of quantification, cut-off and reference values, which provokes uncertainty in the diagnostic sensitivity of necrosis detection.

That is why the goals of analytic quality of the different scientific societies have been: Recommend the use of methods to assess troponin with the maximum analytical sensitivity to increase the diagnostic sensitivity of the test in myocardial necrosis as well as avoiding the problems arising because of the lack of standardization of methods.

\subsection{Guidelines of clinical practice 2007}

In 2007, The Joint ESC/ACF/AHA/ WHF Task Force 2007 (Thygesen 2007) published the last Guidelines of Clinical Practice on the recommendations of the biochemical diagnosis of the detection of ACS and re-define the criteria for Myocardial Infarction establishing a universal definition of AMI. The recommendation (class I) state: In presence of clinical evidence (symptoms or alterations in ECG), concentrations of seric troponin higher than 99th percentile of the interval of reference of the method (with optimal analytic precision $\mathrm{CV}<10 \%$ ), are indicative of myocardial necrosis. If troponin is not available the measurement of CKMB-mass is another acceptable alternative. The extraction of blood must be carried out at patient's admission and 6 - 9 hours after admission. 
These Guidelines are in accordance with the latest analytic recommendations for the use of troponin published in 2007 by the National Academy of Clinical Biochemistry (NACB) and the Committee of standardization of Cardiac Markers of the IFCC (NACB 2007) which state that: To establish reference values $99^{\text {th }}$ percentile must be applied on a population of at least 120 subjects exempt from myocardial damage. It is required that the imprecision of the method in the $99^{\text {th }}$ percentile chosen is lower or equal to a coefficient of variation of $10 \%$.

\section{Methods of new generation: High-sensitivity assays}

The recommendations of these Clinical Guidelines have induced the manufacturers to market methods which assess the protein with higher reliability. This has provoked the appearance in the market of a new generation of immunoassays which assess troponin.

\section{Figure 8. New Generation of Troponin methods}

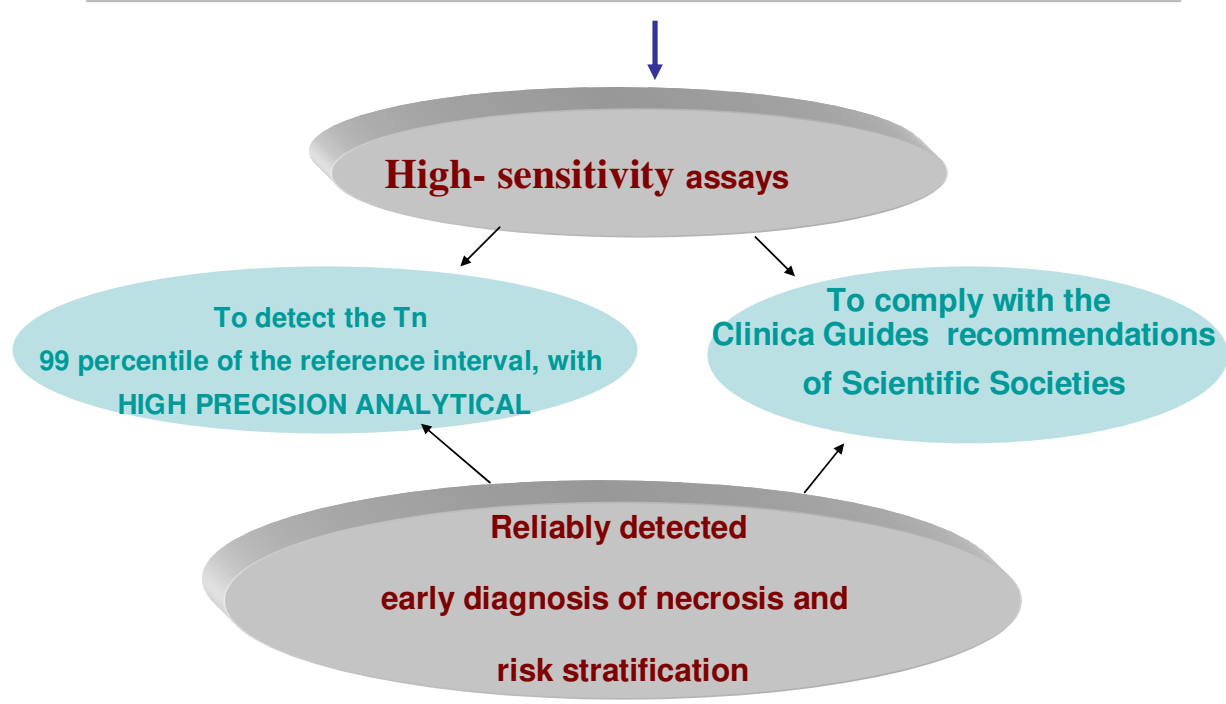

Fig. 8. New generation of troponin methods.

(Figure 8) They are methods with elevated analitic sensitivity and their goal is to detect the 99th percentile of the limit of the detection, quantification limit and normal population with high analitic precision being able to fulfil the recommendations of the scientific societies. The goal of these methods is to be able to know with reliability the early diagnosis of the necrosis and the stratification of myocardial risk. There is a recent publication of Jaffé 2010 which collects the characteristics of analytic sensitivity of all the methods of troponin in the market (table 5, ref Jaffé 2010). 


\begin{tabular}{|c|c|c|c|c|}
\hline $\begin{array}{l}\text { Company-Instrument- } \\
\text { Assay (generation) }\end{array}$ & $\begin{array}{c}\text { Detection } \\
\text { limit } \\
\text { (ug/L) }\end{array}$ & $\begin{array}{l}\text { cTn at 99th } \\
\text { percentile } \\
(\mathrm{ug} / \mathrm{L})\end{array}$ & $\begin{array}{c}\mathrm{CV} \text { at } 99^{\text {th }} \\
\text { percentile }(\%)\end{array}$ & $\begin{array}{c}\text { cTn at } \\
10 \% \mathrm{CV} \\
(\mathrm{ug} / \mathrm{L})\end{array}$ \\
\hline Abbott AxSYM ADV (2nd) & 0.02 & 0.04 & 15.0 & 0.16 \\
\hline Abbott ARCHITECT & $<0.01$ & 0.028 & 15.0 & 0.032 \\
\hline Abbott i-STAT & 0.02 & $0.08^{\#}$ & 16.5 & 0.10 \\
\hline $\begin{array}{l}\text { Beckman Coulter Access } \\
\text { Accu (2nd) }\end{array}$ & 0.01 & 0.04 & 14.0 & 0.06 \\
\hline $\begin{array}{l}\text { bioMerieux Vidas Ultra } \\
\left(2^{\text {nd }}\right)\end{array}$ & 0.01 & 0.01 & 27.7 & 0.11 \\
\hline Innotrac Aio! (2nd) & 0.006 & 0.015 & $\begin{array}{c}14.0 \\
\text { (at } 19 \mathrm{ng} / \mathrm{L})\end{array}$ & 0.036 \\
\hline Inverness Biosite Triage & 0.05 & $<0.05$ & NA & NA \\
\hline Inverness Biosite Triage (r) & 0.01 & 0.056 & 17.0 & NA \\
\hline $\begin{array}{l}\text { Mitsubishi Chemical } \\
\text { PATHFAST }\end{array}$ & 0.008 & 0.029 & 5.0 & 0014 \\
\hline Ortho Vitros ECi ES & 0.012 & 0.034 & 10.0 & 0.034 \\
\hline Radiometer AQT90 & 0.0095 & 0.023 & 17.7 & 0.039 \\
\hline $\begin{array}{l}\text { Response Biomedical } \\
\text { RAMP }\end{array}$ & 0.03 & $<0.1$ & 18.5 & 0.21 \\
\hline Roche E170 & 0.01 & $<0.01$ & 18.0 & 0.03 \\
\hline Roche Elecsys 2010 & 0.01 & $<0.01$ & 18.0 & 0.030 \\
\hline Roche Cardiac Reader & $<0.05$ & $<0.05$ & NA & NA \\
\hline Siemens Centaur Ultra & 0.006 & 0.04 & 10.0 & 0.03 \\
\hline Siemens Dimension RxL & 0.04 & 0.07 & 20.0 & 0.14 \\
\hline $\begin{array}{l}\text { Siemens Immulite } 2500 \\
\text { STAT }\end{array}$ & 0.1 & 0.2 & NA & 0.42 \\
\hline $\begin{array}{l}\text { Siemens Immulite } \\
\text { 1000Turbo }\end{array}$ & 0.15 & NA & NA & 0.64 \\
\hline Siemens Stratus CS & 0.03 & 0.07 & 10.0 & 0.06 \\
\hline Siemens VISTA & 0.015 & 0.045 & 10.0 & 0.04 \\
\hline Tosoh AIA II & 0.06 & $<0.06$ & 8.5 & 0.09 \\
\hline
\end{tabular}

$\mathrm{NA}=$ not assayed $99^{\text {th }}=99^{\text {th }}$ percentile; $10 \% \mathrm{CV}=$ Concentration measured with a $10 \%$ of total imprecision measured as coefficient of variation $(\mathrm{CV}) ;(\mathrm{r})=$ revised assay submitted to FDA per Inverness. Table can be consulted at http://www.ifcc.org/PDF/ScientificActivities/Committees/CSMCD/cTn_Assay_Table_v091209.pdf. Version updated September 12, 2009

Table 5. Analytical characteristics of the current cardiac troponin I and T assays. (source) Troponinas ultrasensibles en el dolor torácico y los síndromes coronarios agudos. ¿un paso hacia delante? A.S. Jaffé y J.Ordoñez-Llanos. Rev Esp Cardiol, 2010; 63(7)763-68

There are only 4 of them which fulfil the recommendations of the Guidelines for Clinical Practice into effect at present (Thygesen 2007), (NCB 2007) $\left(\mathrm{CV}<10 \%\right.$ in $99^{\text {th }}$ percentile). However, at present there is no recommendation in any Clinical Guideline which classifies high sensitivity methods. Apple et al 1999 have suggested a classification to differentiate such methods. They use two criterias a) coefficient of variation in 99th percentile and b) percentege of values detected in reference population. For a method to be ultra-sensitive must have $\mathrm{CV}<10 \%$ in 99 th percentile and detect troponin in less than $50 \%$ of the reference population. 
Table 6 (from Jaffé 2010) holds the classification of the methods available in the market to assess troponin according to the criteria of Apple 1999. None of the 16 methods mentioned in the table fulfil the two conditions Apple demands in their criteria of high sensitivity method

\begin{tabular}{|c|c|c|c|c|}
\hline & $\begin{array}{c}\text { 99th } \\
\text { percentile } \\
\text { (in ng/L) }\end{array}$ & $\begin{array}{c}\text { Imprecision at } \\
\text { 99th percentile } \\
(\%)\end{array}$ & $\begin{array}{l}\text { Classification } \\
\text { according } \\
\text { imprecision }\end{array}$ & $\begin{array}{c}\% \text { of detectable } \\
\text { values in } \\
\text { reference } \\
\text { subjects }\end{array}$ \\
\hline \multicolumn{5}{|c|}{ Current available assays (generation) } \\
\hline Abbott AxSYM ADV (2nd) & 40 & 15.0 & Clinically & $<50 \%$ \\
\hline Abbott ARCHITECT & 28 & 15.0 & Clinically & $<50 \%$ \\
\hline Abbott i-STAT & 80 & 16.5 & Clinically & $<50 \%$ \\
\hline $\begin{array}{l}\text { Beckman Coulter Access } \\
\text { Accu (2nd })\end{array}$ & 40 & 14.0 & Clinically & $50-75 \%$ \\
\hline bioMerieux Vidas Ultra (2nd) & 10 & 27.7 & Not acceptable & $<50 \%$ \\
\hline Innotrac Aio! $\left(2^{\text {nd }}\right)$ & 15 & $14.0($ at $19 \mathrm{ng} / \mathrm{L})$ & Clinically & $<50 \%$ \\
\hline Inverness Biosite Triage & $<50$ & NA & NA & $<50 \%$ \\
\hline Inverness Biosite Triage (r) & 56 & 17.0 & Clinically & Unknown \\
\hline $\begin{array}{l}\text { Mitsubishi Chemical } \\
\text { PATHFAST }\end{array}$ & 29 & 5.0 & Guideline & $<50 \%$ \\
\hline Ortho Vitros ECi ES & 34 & 10.0 & Guideline & $<50 \%$ \\
\hline Radiometer AQT90 & 23 & 17.7 & Clinically & $<50 \%$ \\
\hline Response Biomedical RAMP & $<100$ & 18.5 & Clinically & $<50 \%$ \\
\hline Roche E170 & $<10$ & 18.0 & Clinically & $<50 \%$ \\
\hline Roche Elecsys 2010 & $<10$ & 18.0 & Clinically & $<50 \%$ \\
\hline Roche Cardiac Reader & $<50$ & NA & NA & $<50 \%$ \\
\hline Siemens Centaur Ultra & 40 & 10.0 & Guideline & $<50 \%$ \\
\hline Siemens Dimension RxL & 70 & 20.0 & Clinically & $<50 \%$ \\
\hline $\begin{array}{l}\text { Siemens Immulite } 2500 \\
\text { STAT }\end{array}$ & 200 & NA & NA & $<50 \%$ \\
\hline $\begin{array}{l}\text { Siemens Immulite } 1000 \\
\text { Turbo }\end{array}$ & NA & NA & NA & $<50 \%$ \\
\hline Siemens Stratus CS & 70 & 10.0 & Guideline & $<50 \%$ \\
\hline Siemens VISTA & 45 & 10.0 & Guideline & $<50 \%$ \\
\hline Tosoh AIA II & $<60$ & 8.5 & Guideline & $<50 \%$ \\
\hline \multicolumn{5}{|c|}{ Research high-sensitive assays } \\
\hline $\begin{array}{l}\text { Beckman Coulter Access hs- } \\
\text { cTnI }\end{array}$ & 8.6 & 10.0 & Guideline & $>95 \%$ \\
\hline \begin{tabular}{|l|l} 
Roche Elecsys hs-cTnT \\
\end{tabular} & 13 & 8.0 & Guideline & $>95 \%$ \\
\hline Nanosphere hs-cTnI & 2.8 & 9.5 & Guideline & $75-95 \%$ \\
\hline Singulex hs-cTnI & 10.1 & 9.0 & Guideline & $>95 \%$ \\
\hline
\end{tabular}

Table 6. Classification of the current and the high-sensitive cTn assays according criteria of Apple 2009.(source) Troponinas ultrasensibles en el dolor torácico y los síndromes coronarios agudos. ¿un paso hacia delante? A.S. Jaffé y J.Ordoñez-Llanos. Rev Esp Cardiol, 2010; 63(7)763-68 
From these results it is important to point out that the most sensitive methods (research high-sensitivity assays) that is, with concentration values under 99th percentile and with better imprecisions in such percentile, are the ones which show higher proportion of healthy subjects (between $75-95 \%$ or $>95 \%$ ) which exceed the value of normality established for the method

\section{Repercussion of high sensitivity troponin methods in the management of patients with ACS - Proposal of interpretation in clinical practice}

The appearance of this new generation of high sensitivity troponin methods is going to modify the classical diagnostic interpretation of precordial pain we have been making until now as their goal is to be able to measure much smaller protein concentrations than the ones conventional methods are able to measure now. So it will be necessary to learn again and become familiar with the management of the marker. These new myocardial necrosis biomarkers going to appear in the blood stream hours earlier than if the marker is measured using conventional methods. These ones can only detect troponin 6-9 hours after clinical symptoms whereas using high sensitivity troponin the necrosis can be diagnosed earlier, as it starts being detected in blood three hours after pain. In a similar way the exclusion of acute myocardial infarction will also be earlier and considering the negligible amount of troponin which can be detected it will also increase the prediction of adverse clinical events. There are studies which confirm this fact. As the sensitivity of the methods has increased, it has been found a remarkable increase of the diagnostic sensitivity in the early detection of AMI using all, methods of high sensitivity troponinT and conventional Tn T methods (Giannitsis E,2010, Giannitsis E,2010 b) or troponin I (Kavasak PA 2009. Wilson 2009).

These characteristics which theoretically just show benefits can cause diagnostic confusion of an acute coronary syndrome because ultrasensitive troponin elevations are not only due to an acute process as they are also found in sub-acute processes and other cardiac diseases. High sensitivity troponin methods detect a minimum injury of the non-ischemic cardiomiocites, due to cardiac disorders (myocardial injuries such as myocarditis, pericarditis among others or the increase of the cardiac size as in cardiac insufficiency, left ventricular hypertrophia among others) or to other sort of diseases as for example pulmonary edema, sepsis or ictus can cause the release of hsTn into the systemic circulation. That is why not only the ischemic injury but also a wide range of other alterations can be associated with elevated high sensitivity troponin values. Besides, most of these elevations predict an adverse evolution in these patients, being, in this case, the clinic criterias the only way to reach a diagnosis. This causes confusion in the interpretation of troponin, which has traditionally been associated with the acute coronary syndrome being its elevation essential when the patient has acute thoracic pain, having or not elevation of the ST segment in electrocardiogram. Using conventional methods the finding of troponin values over the reference interval, in processes which do not fit with an acute coronary syndrome, induced us to look into the cause, which habitually was not explained. The appearance of high sensitivity methods make us change our criteria as although the reason for the output into the bloodstream of small amounts of the protein, which were not detected by conventional methods, is not known exactly, in processes which do not fit with acute ischemia its find represents a very useful data for the prognosis of the patient. 
The appearance of this new generation of methods to assess troponin induces us to continue with the research in the management of these biomarkers, whose future is promising, in order to optimize and learn its management, and until new Guidelines in Clinical Practice appear and reach a consensus on the best way to use and interpret the results, we must be cautious in the application of high sensitivity troponin in clinical practice methods.

That is why the best thing to do (table 7) before implementing a method in clinical practice is to assess comprehensively and establish the reference values in better defined populations, using more strict inclusion criteria, setting up patterns of evolution changes to differentiate an ischemic patient from a patient with troponin elevations due to stable disease or underlying to new pathologic entities different from acute coronary syndrome. The knowledge this data for each of the methods assessing ultrasensitive troponin is an essential tool for the correct use and clinical interpretation of the results. Not to have such data well defined and established makes the diagnostic interpretation difficult and can cause confusion

1. Establishing reference values (99 th percentil discriminator at CV $<10 \%$ )

2. Establishing the increase value of high sensitivity troponin discriminator of Acute Coronary Syndrome ( $\Delta$ Tn discriminator).

Table 7. Mandatory requirements for the use of a high sensitivity troponin method in clinical practice

\subsection{Establishing reference values of the method}

As it can be seen in table 7 when there is an increase in the analytical sensitivity of the troponin tests, there are more people with troponin concentration over the 99th percentile. So, individuals with cardiovascular risk as hypertension, dislipemia, diabetes, renal insufficiency, cardiac insufficiency among others. This fact can make the clinical interpretation of the test difficult. That is why when evaluating a high sensitivity troponin method we must be especially cautious when establishing the reference values (table 8). The selection of the individuals to be included as reference population must be much more selective, considering much more strict inclusion criteria. The most important exclusion criteria to bear in mind are: pregnancy, current cold or infection, chronic inflammatory disease, patients treated for cardiac disease or lipid management, diabetes, family history of cardiovascular disease, smoking, high blood pressure or treated for high blood pressure, increased C-reactive protein, o interleukin- 6 among others. The number of subjects to study must be at least 120 and $99^{\text {th }}$ percentile will be applied. The imprecision of the method in the 99th percentil chosen must be lower or equal to a coefficient of variation of $10 \%$ (NACB 2007). We must bear in mind that the value of the 99 th percentile chosen must be higher than the value measured by the method with an imprecision lower than $10 \%$ (99th percentil discriminator). We could expect that if we carried out again reference values in the methods mentioned in tables 5 and 6, with more restrictive inclusion criteria applied, especially in the ones called (research high-sensitivity assays), the percentage of detectable troponin in normal subjects, exempt from cardiovascular pathology, would decrease. 
Evolution of Biochemical Diagnosis of

\begin{tabular}{|l|l|}
\hline Number of patients & Mínimum de 120 subjects \\
\hline & - pregnancy \\
& - infection \\
& - chronic inflammatory disease \\
Exclusion criteria & - subjets treated for cardiac disease or lipid management \\
& - diabetes \\
& - subjects with family history of cardiovascular disease \\
& - smoking \\
\hline statistic & - increased C-reactive protein or interleukin-6 \\
\hline Precision & 99 th percentile \\
\hline
\end{tabular}

Table 8. Requirements to establish reference values of high sensitivity troponin methods

\subsection{Establish the value of increase of high sensitivity troponin discriminator of acute coronary syndrome}

As a result of all the above mentioned it is easy to understand the difficulty in interpreting a value of basal high sensitivity troponin in patients who go to the emergency room with precordial pain and without conclusive alterations in the electrocardiogram. From the biochemical point of view, the only way to help to distinguish if a high sensitivity troponin elevation is due to an acute ischemia process or if the origin is a sub-acute cardiac disease or chronic, as it happens with congestive cardiac insufficiency or cardiomyiopaties among others, is to perform serial troponins, as the Guidelines for Clinical Practice in 2007 recommended (Thygesen 2007, NACB 2007). Nevertheless, given the early of the appearance of high sensitivity troponin (3 hours after pain) as well as its high sensitivity in detection, the basal determination and the determination 6-9 after pain would not be the protocol to choose. With these new generation of troponins, the advisable to distinguish if we are facing an acute necrosis process or an underlying ischemia of a chronic process, is to establish a value of the increase of troponin discriminator of acute coronary syndrome ( $\Delta$ Tn discriminator). To obtain this data the increase in the variation of troponin should be assessed for a 3-hour interval, in a group of patients who suffer from an acute coronary syndrome and in another group patients who suffer a chronic process. In the acute ischemia there will be a significant increase of basal troponin compared with the one carried out between 3 and 6 hours later. In chronic processes the increase in troponin between 3 and 6 hours compared with basal troponin will be much lower. Once the Tn discriminator for a determined method is obtained, in clinical practice the scheme in figure I could be applied, which will help us confirm an acute myocardial infarction, at an earlier stage than with traditional methods, or to look for other causes of the increase in troponin.

The correct establishment of the increase evolution of high sensitivity troponin for an acute coronary syndrome, together with the strict study of normality values will clarify the advantages of this new generation of methods for the early diagnosis of acute coronary syndrome, as well as it will significantly benefit in the stratification of the risk, not only in patients with acute coronary syndrome but also patients who suffer from other myocardial injuries or increase of cardiac size among other causes. 


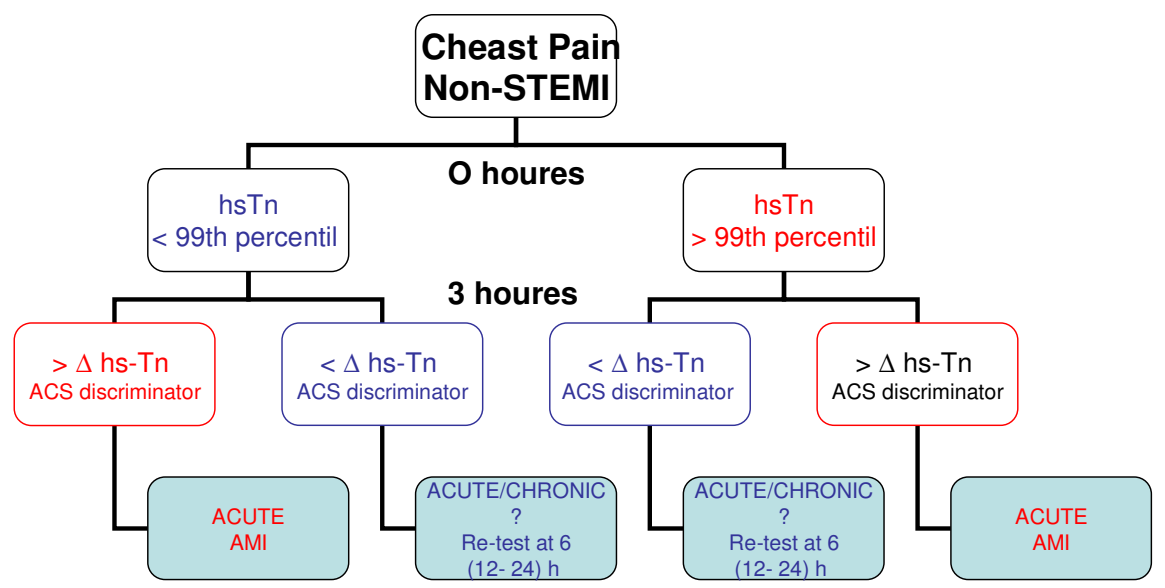

$\Delta$ hs-Tn ACS discriminator: troponin increase ACS discriminator

AMI: Acute myocardial infarction

ACS: Acute coronary syndrome

Fig. 9. Clinical significance of hsTn using troponin increase ACS discriminator. Proposal for the use of high sensitivity troponin in clinical practice.

\section{High sensitivity troponin in patients with heart failure}

Heart failure (HF) is a growing public health problem with high morbidity and mortality (Rosamond W 2008) . Natriuretic peptides are the election markers for diagnosis and risk stratification of patients with Heart failure ( Braunwald E 2008) . Cardiac troponin are detected in an important proportion of patients suffering from acute or chronic HF. The mechanism of cardiac damage and appearance in Tn plasma, acute or chronic HF is not exactly known. The levels of troponin in plasma are associated with the increase of the risk of morbility and mortality either in acute or chronic HF giving prognostic information (Parentini 2008). Cardiac troponin is detected in a significant portion of patients with acute and chronic Heart Failure. However, the incidence of detection depends on the sensitivity of the assay used. Latini et al ( Latini 2007) ,. measured Plasma troponin T in 4053 patients with chronic HF enrolled in the Valsartan Heart Failure Trial (Val-HeFT). Troponin $\mathrm{T}$ was detectable in $10.4 \%$ of the population with the conventional cTnT assay (detection limit $<$ or $=0.01 \mathrm{ng} / \mathrm{mL}$ ) compared with $92.0 \%$ with the new hsTnT assay (< or $=0.001 \mathrm{ng} / \mathrm{mL}$ ). Detectable cTnT predicts adverse outcomes in chronic HF. (High sensitivity Troponin T (hsTnT) is a novel biomarker that provides prognostic information in several clinical settings as heart failure.

\section{Conclusions}

In view of all the above mentioned we can conclude that the biochemical diagnosis of ACS continues being a current affair and continues envolving. The process of troponin has not finished yet. The appearance of high sensitivity methods seems to be promising. They help to diagnose ACS much earlier and obtain higher stratification of the risk than convencional 
methods. Besides, it will let us know about the prognostic evolution of other pathologies such as chronic cardiac insufficiency as well as cardiovascular events in stable coronary disease. Nevertheless, to achieve the efficiency that the test deserves we have to learn, again to use and interprete the results of ultra-sensitive troponin. It is necessary to consolidate and establish firmly the dynamic changes of troponin concentrations to interprete the results accurately.

\section{References}

Apple FS, Adams JE, Wu Alan HB, Jaffe AS. Report on a survey of analytical and clinical characteristics of commercial cardiac troponin assays. In Markers in cardiology: current and future clinical applications. Armonk, NY 2001,4,31

Apple FS. A new season for cardiac troponin assays: It's time to keep a scorecard. Clin Chem 2009; 55:1303-6.

Braunwald E Biomarkers in heart failure.. N Engl J Med. 2008 (20):2148-59

The Joint European Society of Cardiology/ American College of Cardiology Committe. Consensus Document. Myocardial infarction redefined. A consensus document of the Joint European Society of Cardiology/American College of Cardiology Committe for the Redefinition of Myocardial Infarction. Eur Heart J 2000;21:150213.

Galán A. Diagnóstico Bioquímico de la Isquemia Coronaria Aguda Medicina Clínica 2000; 115(17) :671-676

Galán, A, Curos, J Durán. A.Corominas ,V.Valle Analytical evaluation of two automatic methods to measure blood CK-MB mass an Troponin I Journal of Automated Methods and Management in Chemistry 2002;24(2):51-57

Galán, A. Curós y A. Corominas. Interés de las troponinas en el síndrome coronario agudo en pacientes con insuficiencia renal. Medicina Clínica, 2004;123:551-6

Giannitsis E, Katus AH. Myocardial infarction. Current recommendation for interpretation of highly sensitive troponin $\mathrm{T}$ assay for diagnostic, therapeutic and pronostic puposes in patients with a non-ST-segment - elevation acute coronary Syndrome. European Cardiology 2009; 5(2): 44-47

Giannitsis E, Kurz K, Hallermayer K, Jarausch J, Jaffe AS, Katus AH. Analytical validation of a high-sensitivity cardiac troponin T assay. Clin Chem 2010; 56:254-61.

Giannitsis E, Becker M, Kurz K, Hess G, Zdunek D, Katus HA. High-sensitivity cardiac troponin $\mathrm{T}$ for early prediction of evolving non-ST-segment elevation myocardial infarction in patients with suspected acute coronary syndrome and negative troponin results on admission. Clin Chem 2010; 56:642-50.

Jaffé A.S. J.Ordoñez-Llanos J. Troponinas ultrasensibles en el dolor torácico y los síndromes coronarios agudos. ¿un paso hacia delante? Rev Esp Cardiol, 2010; 63(7)763-68

Kavsak PA, MacRae AR, Yerna MJ, Jaffe AS.Analytic and clinical utility of a next-generation, highly sensitive cardiac troponin I assay for early detection of myocardial injury. Clin Chem 2009 ;55(3):573-7

Latini R, Masson S, Anand IS, Missov E, Carlson M, Vago T, Angelici L, Barlera S, Parrinello G, Maggioni AP, Tognoni G, Cohn JN; Val-Heft Prognostic value of very low 
plasma concentrations of troponin $\mathrm{T}$ in patients with stable chronic heart failure. Circulation 2007;116(11):1242-9.

(NACB) National Academy of Clinical Biochemistry. National Academy of Clinical Biochemistry Laboratory medicine practice guidelines: clinical characteristics and utilization of biochemical markers in acute coronary syndromes. Clin Chem 2007; 53: 552-574.

Panteghini M, Gerhardt W, Apple FS, Dati F, Ravkilde J, Wu AH. Quality specifications for cardiac troponin assays. Clin Chem Lab Med. 2001;39:174-8.

Parenti N, Bartolacci S, Carle F, Angelo Cardiac troponin I as prognostic marker in heart failure patients discharged from emergency department. Intern Emerg Med. 2008 Mar;3(1):43-7.

Rosamond W Lloyd-Jones D, Adams R, Carnethon M, De Simone G, Ferguson TB, Flegal K, Ford E, Furie K, Go A, Greenlund K, Haase N, Hailpern S, Ho M, Howard V, Kissela B, Kittner S, Lackland D, Lisabeth L, Marelli A, McDermott M, Meigs J, Mozaffarian D, Nichol G, O'Donnell C, Roger V, , Sacco R, Sorlie P, Stafford R, Steinberger J, Thom T, Wasserthiel-Smoller S, Wong N, Wylie-Rosett J, Hong Y; American Heart Association Statistics Committee and Stroke Statistics Subcommittee. Heart disease and stroke statistics--2009 update: a report from the American Heart Association Statistics Committee and Stroke Statistics Subcommittee Circulation. 2010 Jul 6;122(1):e11.

Thygesen K, Alpert JS, White HD. White on behal of the Joint ESC/ACF/AHA/ WHF Task Force for the Redefinition of Myocardial Infarction. Universal definition of myocardial infarction. European Heart J. 2007;28:2525-2538

WHO Report of the Joint International Society and Federation of Cardiology / World Health Organization Task Force on Standardization of Clinical Nomenclature.Circulation 1979;59:607-609

Wilson SR, Sabatine MS, Braunwald E, Sloan S, Murphy SA, Morrow D. Detection of myocardial injury in patients with unstable angina using a novel nanoparticle cardiac troponin I assay: Observations from the PROTECT-TIMI 30 Trial. Am Heart J 2009; 158:386-91.

Wu AHB, Apple FS, Gibler WB, Jesse RL, Warshaw MM, Valdes R, Jr. National Academy of Clinical Biochemistry Standards of Laboratory Practice: recommendations for use of cardiac markers in coronary artery diseases. Clin Chem 1999;45:1104-1121

Wu Alan HB Analytical issues affecting the clinical performance of cardiac troponin assays. In Markers in cardiology: current and future clinical applications. Armonk, NY $2001,1,1$ 


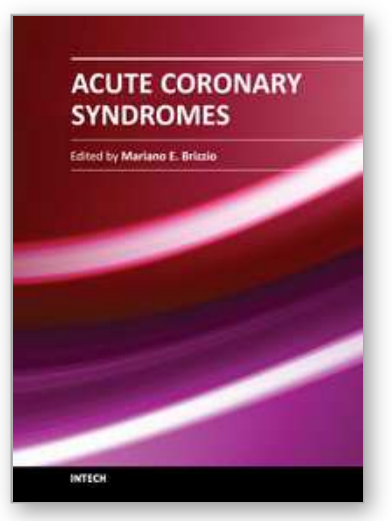

\author{
Acute Coronary Syndromes \\ Edited by Dr. Mariano Brizzio
}

ISBN 978-953-307-827-4

Hard cover, 214 pages

Publisher InTech

Published online 24, February, 2012

Published in print edition February, 2012

This book has been written with the intention of providing an up-to-the minute review of acute coronary syndromes. Atherosclerotic coronary disease is still a leading cause of death within developed countries and not surprisingly, is significantly rising in others. Over the past decade the treatment of these syndromes has changed dramatically. The introduction of novel therapies has impacted the outcomes and surviving rates in such a way that the medical community need to be up to date almost on a "daily bases". It is hoped that this book will provide a timely update on acute coronary syndromes and prove to be an invaluable resource for practitioners seeking new and innovative ways to deliver the best possible care to their patients.

\title{
How to reference
}

In order to correctly reference this scholarly work, feel free to copy and paste the following:

Amparo Galán, Josep Lupón and Antoni Bayés-Genis (2012). Evolution of Biochemical Diagnosis of Acute Coronary Syndrome - Impact Factor of High Sensitivity Cardiac Troponin Assays, Acute Coronary Syndromes, Dr. Mariano Brizzio (Ed.), ISBN: 978-953-307-827-4, InTech, Available from:

http://www.intechopen.com/books/acute-coronary-syndromes/evolution-of-biochemical-diagnosis-of-acutecoronary-syndrome-impact-factor-of-highly-sensitive-card

\section{INTECH}

open science | open minds

\section{InTech Europe}

University Campus STeP Ri

Slavka Krautzeka 83/A

51000 Rijeka, Croatia

Phone: +385 (51) 770447

Fax: +385 (51) 686166

www.intechopen.com

\section{InTech China}

Unit 405, Office Block, Hotel Equatorial Shanghai

No.65, Yan An Road (West), Shanghai, 200040, China 中国上海市延安西路65号上海国际贵都大饭店办公楼 405 单元

Phone: +86-21-62489820

Fax: +86-21-62489821 
(C) 2012 The Author(s). Licensee IntechOpen. This is an open access article distributed under the terms of the Creative Commons Attribution 3.0 License, which permits unrestricted use, distribution, and reproduction in any medium, provided the original work is properly cited. 